\title{
Ensino, monitoria e promoção da saúde em tempos de pandemia da COVID-19
}

\author{
Teaching, monitoring and promoting health in times of COVID-19 pandemic \\ Enseñar, monitorear y promover la salud en tiempos de pandemia COVID-19
}

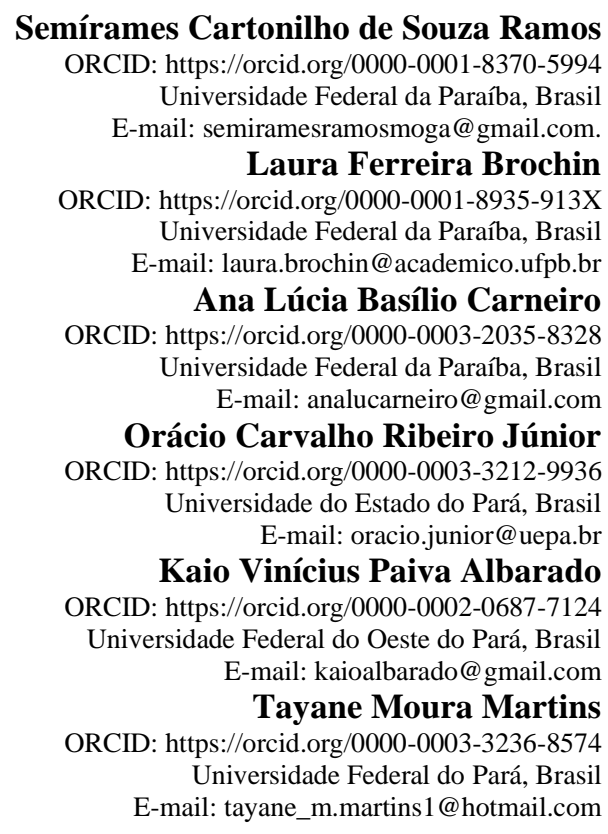

\begin{abstract}
Resumo
Objetivo: Discorrer sobre as experiências no processo de ensino e monitoria remotos, com o olhar na promoção da saúde, em tempos de pandemia. Método: Estudo do tipo relato de experiência com abordagem qualitativa, descritiva e exploratória, realizado a partir das vivências e interações promovidas através dos encontros síncronos e assíncronos entre docente, discente-monitor e discentes do Curso de Enfermagem, na disciplina de Metodologia do Trabalho Científico, com carga horária de 30 horas, do Departamento de Enfermagem em Saúde Coletiva da Universidade Federal da Paraíba (UFPB). Resultados: As atividades foram planejadas e organizadas em três etapas principais, acolhimento, desenvolvimento do conteúdo programado e encerramento. Desenvolveram-se de forma síncrona e assíncrona, utilizando as seguintes plataformas e aplicativos: Google (Meet, Forms, Docs e Agenda), Moodle Classes, e-mail e WhatsApp. A maioria dos (15) discentes era do sexo feminino, treze (13) foram aprovados (87\%). Em todos os encontros síncronos foram utilizados diferentes recursos culturais e estratégias para o cuidado e promoção da saúde (músicas, poemas, parábolas e dinâmicas de quebra gelo) para acolher, desenvolver e encerrar as atividades. A monitoria foi dinâmica e criativa utilizando tecnologias de informação e comunicação. Considerações Finais: O ensino e a monitoria com um olhar no cuidado e promoção da saúde, foram um desafio em tempos de pandemia, uma experiência única e importante componente de contribuição para o êxito do processo de formação acadêmica no formato de ensino remoto. Desenvolveu-se um novo olhar e modo de fazer que permitiu avançar e cuidar no processo de ensino aprendizagem.
\end{abstract}

Palavras-chave: Estudantes de enfermagem; Educação a distância; COVID-19; Tecnologia; Ensino.

\begin{abstract}
Objective: To discuss the experiences in the remote teaching and monitoring process, with a view to care, in times of pandemic. Method: An experience report type study with a qualitative, descriptive and exploratory approach, carried out based on the experiences and interactions promoted through virtual meetings between professor, student-monitor and students of the Nursing Course, in the discipline of Methodology of Scientific Work, with 30-hour workload, from the Department of Nursing in Collective Health at the Federal University of Paraíba (UFPB). Results: The activities were planned and organized in three main stages, reception, development of the programmed content and closure. They developed synchronously and asynchronously, using the following platforms and applications: Google (Meet, Forms, Docs and Agenda), Moodle Classes, e-mail and Whatsapp. Most of the (15) students were female, thirteen (13) were approved (87\%). In all synchronous meetings, different cultural resources and strategies for the care and promotion of health (songs, poems, parables and ice breaking dynamics) were used to welcome, develop and close the activities. The
\end{abstract}


monitoring was dynamic and creative using information and communication technologies. Conclusion: Teaching and monitoring with a view to care and health promotion, were a challenge in times of pandemic, a unique experience and an important component of contribution to the success of the academic education process in the format of remote teaching. A new look and way of doing was developed that allowed advancing and taking care of the teaching-learning process.

Keywords: Nursing students; Distance education; COVID-19; Technology; Teaching.

\section{Resumen}

Objetivo: Discutir experiencias en el proceso de enseñanza y seguimiento a distancia, con miras a promover la salud en tiempos de pandemia. Método: Estudio tipo informe de experiencia con enfoque cualitativo, descriptivo y exploratorio, realizado a partir de las experiencias e interacciones promovidas a través de encuentros sincrónicos y asincrónicos entre profesor, alumno-monitor y alumnos del Curso de Enfermería, en la asignatura de Metodología del Trabajo Científico, con una carga de trabajo de 30 horas, del Departamento de Enfermería de Salud Pública de la Universidad Federal de Paraíba (UFPB). Resultados: Las actividades se planificaron y organizaron en tres etapas principales, recepción, desarrollo de contenidos programados y cierre. Fueron desarrollados de forma sincrónica y asincrónica, utilizando las siguientes plataformas y aplicaciones: Google (Meet, Forms, Docs y Agenda), Moodle Classes, email y WhatsApp. La mayoría (15) estudiantes eran mujeres, trece (13) fueron aprobados (87\%). En todos los encuentros sincrónicos se utilizaron diferentes recursos culturales y estrategias de atención y promoción de la salud (canciones, poemas, parábolas y dinámicas rompehielos) para acoger, desarrollar y cerrar las actividades. El seguimiento fue dinámico y creativo utilizando tecnologías de la información y la comunicación. Consideraciones finales: La docencia y el seguimiento con miras a la atención y promoción de la salud fueron un desafío en tiempos de pandemia, una experiencia única y un componente importante de contribución al éxito del proceso de formación académica en el formato de aprendizaje a distancia. Se desarrolló una nueva mirada y forma de hacer las cosas que permitió avanzar y cuidar en el proceso de enseñanza-aprendizaje.

Palabras clave: Estudiantes de enfermería; Educación a distancia; COVID-19; Tecnología; Enseñanza.

\section{Introdução}

Em virtude do advento relacionado à pandemia que assolou o mundo a partir de um surto da COVID-19, identificado na China no final de 2019 (Zhou et al. 2020), diversas medidas de prevenção foram adotadas para controlar e diminuir o número de casos, como a quarentena e isolamento social, resultando na paralisação e fechamento de diversos estabelecimentos, dentre eles as instituições de ensino.

Diversos setores socioeconômicos foram impactados pela pandemia, dentre eles a educação, a partir de momento em que foi decretado o fechamento das instituições como medida para conter a disseminação do vírus e controlar a curva de infecção (Aristovnik et al. 2020). A adoção do ensino remoto foi uma alternativa encontrada por órgãos educacionais para minimizar os impactos no calendário acadêmico dos estudantes e as lacunas do conhecimento resultantes da pandemia da COVID-19 (Murphy, 2020).

Os atores precisaram lançar mão de recursos digitais menos utilizados anteriormente, o que trouxe desafios a essa nova realidade. Há disciplinas com especificidades que são mais difíceis em se desempenhar remotamente. As considerações acerca do desempenho e conhecimento com relação à tecnologia de cada discente, pode resultar em desigualdade entre os estudantes, tornando-se um obstáculo a se superar no novo cenário remoto (Stott \& Mozer 2016; Fawaz \& Samaha, 2020; Lovri’c et al. 2020).

A progressão do surto e a elevada taxa de mortalidade desencadeou na população mundial o aumento dos transtornos psicológicos, em especial nos universitários. O isolamento e os novos padrões de ensino à distância resultaram na diminuição do desempenho acadêmico e problemas psíquicos como estresse e depressão em graduandos de enfermagem (Othman et al. 2019). Atentas aos fatos e às estatísticas, a docente percebeu a necessidade de agregar ao processo de ensino aprendizagem uma abordagem humanística, vislumbrando o cuidado e a promoção da saúde dos discentes, da monitora e da própria docente.

Nessa perspectiva, a Universidade Federal da Paraíba (UFPB) realizou algumas adequações. Uma delas foi através da Resolução 19/2020 na qual foi determinado e instituído um Período Suplementar realizado por meio de ensino remoto (Resolução n 19/2020 de 06 de agosto de 2020 da Universidade Federal da Paraíba). A partir dessa decisão, diversas atividades acadêmicas 
passaram a ser ofertadas nessa modalidade. Considerando o momento de crise desencadeado pela pandemia, foi adequada ao novo formato de atividade remota a Monitoria, instrumento de apoio pedagógico que oportuniza ao discente-monitor desenvolver práticas docentes (Andrade et al. 2018).

A UFPB conta com um programa de Monitoria regulamentado pela Resolução nº 02/1996, cujo objetivo é despertar o interesse pela docência e minimizar problemas decorrentes de abandono de curso, repetência e ausência de motivação dos estudantes, possivelmente acentuados na pandemia, na qual esse público está comumente mais exposto ao desenvolvimento de estresse e depressão e os obstáculos impostos pela quarentena pode ser um forte influenciador nesse processo (Resolução n $02 / 96$ de 22 de fevereiro de 1996 da Universidade Federal da Paraíba). Com o advento da pandemia da COVID-19 e exigências impostas, a UFPB lançou o Edital Simplificado no 018/2020 da Coordenação de Programas e de Projetos Acadêmicos, onde normatizou a Monitoria em formato remoto e considerou a imprescindibilidade do uso de tecnologias de comunicação remota e de Ambientes Virtuais de Aprendizagem (AVA) pelos docentes e discentes nas práticas pedagógicas cotidianas durante a execução do Calendário Suplementar. Com isso, houve a necessidade de desenvolver programas que contribuam para a saúde e o bem-estar dos discentes e docentes da UFPB, considerando o momento de crise desencadeado pela pandemia do novo coronavírus (Edital Simplificado n ${ }^{\circ} 8 / 20$ de 11 de agosto de 2020 da Universidade Federal da Paraíba).

As atividades remotas constituíram um novo e grande desafio para a comunidade acadêmica. Seu início se deu de forma abrupta sem possibilidade de um período de transição e adaptação ao novo formato. Trouxe consigo um caráter de emergencialidade e uma urgente necessidade de adaptação e aplicação de recursos até então pouco utilizados. Vimos surgir uma transposição do ensino presencial para o remoto (online), onde as incertezas permearam as atitudes e tomada de decisões. A tradicional sala de aula foi substituída pelo ambiente virtual onde ao mesmo tempo esse espaço se misturava com outros ambientes da casa, da rua, da recepção do consultório, trazendo uma nova realidade e uma necessidade maior de disciplina, interatividade, domínio de tecnologias e capacidade de concentração e adaptação. Foi necessário lançar mão das novas Tecnologias de Informação e Comunicação (TICs), tais como Zoom, Moodle, Skype, Google Meet, dentre outras, como ferramenta de ensino, trazendo à carreira dos educadores e educandos novos desafios a serem alcançados (Jowsey et al. 2020).

$\mathrm{O}$ isolamento e a quarentena, impostos pela pandemia, exigiu dos educadores atualizações para o uso das novas tecnologias, modificações para a manutenção da aprendizagem no formato remoto e um novo olhar para a demanda educacional e pessoal dos estudantes durante o ensino remoto (Morcillo et al. 2020). A UFPB, em contrapartida, ofereceu diversos cursos no intuito de instrumentalizar estudantes e professores entre eles Curso sobre Aplicativos do Google (Google Groups, Forms, Drive, Docs, Agenda) e ferramentas de gamificação para sala de aula (Quizziz \& e Kahoot); o curso de Docência Digital; Curso Preparatório para o Uso de Tecnologias Digitais no Ensino, e Discente Digital.

Estudos demonstraram baixa adesão às aulas realizadas à distância, cuja causa encontra-se nas limitações do ensino online, como a distância física entre discentes e docentes e ao ambiente fora da sala de aula presencial. Os estudantes se viram fora do habitual modo de ensino para um que exige disciplina e proatividade para a produção de seu próprio aprendizado. Dessa forma, junto à necessidade do aprofundamento acerca das plataformas digitais, houve também a exigência de uma abordagem mais dinâmica e acolhedora, com o intuito de estimular o discente a participar ativamente das aulas e manter presente a interação entre educadores e educandos, minimizando o medo e dificuldades diante do novo (Leigh et al. 2020; Martini, 2017; Neto, 2017). Sendo assim, esse estudo acadêmico teve por finalidade discorrer sobre as experiências relativas ao processo de ensino e monitoria no formato remoto com enfoque humanístico em tempos de pandemia.

\section{Metodologia}

Esse estudo do tipo relato de experiência apresenta uma abordagem qualitativa, através da observação participante e descritiva, realizado a partir das vivências nos encontros assíncronos e síncronos, realizados na Plataforma do Google Meet, na 
disciplina de Metodologia do Trabalho Científico, com carga horária de 30 horas, componente curricular do Departamento de Enfermagem em Saúde Coletiva da Universidade Federal da Paraíba (UFPB). As atividades foram desenvolvidas durante os meses de setembro a dezembro de 2020, em ambiente síncrono, virtual e assíncrono. O estudo caracteriza-se por uma população de 17 participantes sendo uma (1) docente, quinze (15) discentes e uma (1) monitora. Os encontros online foram realizados às quartas-feiras e o link de participação disponibilizado via WhatsApp e e-mail.

As atividades virtuais na disciplina de Metodologia do Trabalho Científico, ocorreram no período de setembro a dezembro de 2020, via web conferência, Google Meet, Moodle Class e chats online. Os encontros síncronos ocorreram regularmente às quartas-feiras, durante duas horas. As monitorias foram realizadas, em grupo e individualmente, de acordo com a disponibilidade dos discentes. Todas as atividades observadas foram transcritas para um diário de campo e, posteriormente, analisadas gerando temas de acordo com os fatos verificados.

\section{Resultados e Discussão}

Os resultados a seguir foram coletados a partir de uma população em sala de aula da UFPB. Foi organizado a partir das variáveis gênero, número de aprovações, quantidade de alunos que trancaram a disciplina e quantitativo de discentes faltosos. Dos quinze (15) matriculados, a maioria era do sexo feminino (64,29\%), treze (13) discentes foram aprovados na disciplina (86,6\%), um (1) estudante trancou a disciplina $(6,7 \%)$ e um (1) não compareceu aos encontros $(6,7 \%)$. As atividades foram divididas em encontros síncronos e assíncronos. Estas experiências serão descritas a seguir.

\subsection{Ensino, cuidado e promoção da saúde: acolhimento, desenvolvimento e encerramento na sala de aula virtual}

Diante da distância, isolamento social e sofrimento psíquico impostos pela pandemia, entendeu-se a necessidade de favorecer e proporcionar ao discente, além das atividades inerentes ao ensino, atividades que pudessem contribuir com a promoção da saúde e o bem estar físico e mental onde o discente se sentisse acolhido, participante, corresponsável pelas atividades, respeitado na sua individualidade e motivado a participar e colaborar.

Segundo Neto (2017) o ambiente de ensino-aprendizagem virtual deve ser acolhedor e proporcionar interação através do diálogo. O vocábulo acolher possui outros significados como: agasalhar, refugiar, resguardar, proteger, apoiar, amparar. O acolhimento faz parte das diretrizes da Política Nacional de Humanização do Sistema Único de Saúde no Brasil e é primordial que a experimentação de acolhimento seja vivida na academia, o que certamente irá favorecer na formação de um Enfermeiro mais sensibilizado e humanizado (Brasil, 2007).

Nos encontros síncronos o bem-estar, o suporte social e o acolhimento foram oferecidos através de múltiplos artifícios. Ao iniciar os encontros todos eram recebidos com palavras de acolhimento, boas-vindas e de estímulo, valorizando a presença e a participação, demonstrando interesse pela pessoa através do discente. As atividades eram pensadas para proporcionar também o vínculo, a oportunidade de fala, escuta e a aproximação dos atores envolvidos no processo de ensino-aprendizagem. O acolhimento virtual era feito através da inserção de algumas músicas de artistas como Tiago Iorc, Katy Perry e Ed Sheeran, que contribuíram para um ambiente de companheirismo, amor e amizade (Barreto, 2008).

Realizou-se a leitura de versos (Bessa, 2018) e poesias (Pizzimenti, 2017), valorizando assim a cultura, onde foi possível a abertura das portas para a liberdade, equidade e diálogo, enquanto elemento gregário que traz significados às relações humanas (Brant, 2009). Foram efetuados algumas dinâmicas como a do quebra gelo (Martini, 2017), motivação e relaxamento, vídeos divertidos ou motivacionais. As leituras de parábolas (Prieto \& Saxe, 2021) tiveram a finalidade de promover o sentir da vida, onde ocasionou o desenvolvimento da consciência e troca afetiva (Martini, 2017). Havia ainda os momentos de celebração onde era oportunizada a fala sobre coisas boas vividas durante a semana como aniversários, conquistas ou momentos marcantes. Diversos discentes relataram a importância do acolhimento, demonstrando gratidão, alívio de tensões e sentimento de pertencer. 
Durante o desenvolvimento das atividades foi sendo constituída o fortalecimento da participação do discente, oportunizando a fala, a elaboração e compartilhamento de atividades promovendo a responsabilização coletiva do ensinoaprendizagem de forma interessante e dinâmica com o objetivo de evitar distrações. Foram promovidos períodos de pausas para um pequeno lanche e para a realização de pequenas atividades de alongamento.

Diante dos desafios, a criatividade e a interação com o discente, envolvendo-o e criando um sentimento de responsabilidade e de pertencimento, deram fôlego para que o grupo avançasse nas atividades em casa, após a atividade síncrona. Os encontros semanais traziam sempre atividades relativas ao conteúdo ministrado onde os discentes tinham que construir gradativamente as etapas que iam sendo discutidas a cada encontro síncrono; a exemplo quando ministrado o conteúdo relativo aos aspectos éticos da pesquisa com seres humanos, os discentes foram apresentados virtualmente à Plataforma Brasil e como atividade elaboraram o Termo de Consentimento Livre Esclarecido. Assim, todos os conteúdos discutidos nos encontros síncronos eram transformados em uma atividade, juntando a teoria e a prática.

Ao final do encontro síncrono era feito um rápido ritual de encerramento com utilização de componentes da cultura como poesia, contos, música e/ou vídeos para promover um ambiente agradável. Além disso, eram reforçadas as orientações sobre as atividades a serem realizadas para o próximo encontro e disponibilização de conteúdo.

\subsection{Encontros síncronos e Assíncronos: ensino e monitoria}

O universo tecnológico oferece muitas possibilidades e alternativas pedagógicas. Os encontros síncronos realizados por web conferência, foram organizados em etapas: planejamento, acolhimento, desenvolvimento do conteúdo programado e encerramento. O planejamento seguiu duas etapas principais, de acordo com a metodologia descrita por Dotta (2014) "contextualização (qual a faixa etária e número de discentes, conhecimento anterior do tema, qual a abordagem seria utilizada, dinâmica a ser adotada e infraestrutura necessária); requisitos (pedagógicos e técnicos).”.

A monitoria compreendeu que para alcançar êxito nessa modalidade de ensino deveria haver um compromisso com o planejamento, organização e autonomia, além da preocupação em desenvolver formas de abordagem mais atrativas e eficientes. Dessa forma, foi possível gerar uma contribuição positiva com os discentes na elaboração de cronogramas e estabelecimento de etapas e prazos. A prática educativa é um ato de permitir aos discentes assumirem-se como seres que pensam, criam e recriam através da ação reflexão (Freire, 2020).

Já durante as atividades assíncronas, foram utilizadas diversas ferramentas: Fórum ou Lista de discussão, E-mail, WhatsApp e abordados e fortalecidos os conteúdos anteriormente discutidos, a fim de esclarecer possíveis dúvidas e proporcionar maior apreensão das informações e contribuir na elaboração das atividades exigidas. A monitora implantou plantão tira dúvidas, contribuindo com a organização na nova rotina.

Foi formado um grupo no WhatsApp onde todos tinham acesso e liberdade para procurar as informações e materiais necessários disponíveis na plataforma. Esse espaço também se destinava ao suporte emocional e social ao estabelecer relações de cooperação, amizade e ajuda mútua.

No entanto, as atividades eram solicitadas para a composição do conhecimento, como leitura de material didático, artigos, livros, estudos sobre o uso de ferramentas e aplicativos como o Ryyan (Ouzzani et al. 2016), EndNote (Vianna, 2018), Mendeley e ferramentas do Google; uso de filmes e Podcasts e atividades para compor o processo de avaliação somatória. Uma das atividades consistiu na elaboração de um resumo sobre o filme A Teoria de Tudo, que é uma cinebiografia que trata da vida do cientista Stephen Hawking reconhecido pelas suas contribuições à ciência no estudo do Universo. Utilizou-se os princípios da Teoria de Paulo Freire que nos provoca a refletir que ensinar traduz o exercício do diálogo, da troca, da reciprocidade, de um tempo para falar, aprender e ensinar (Freire, 2020). 
Nesse caso, a utilização do ensino remoto, ferramentas digitais e as TICs trouxeram reflexões sobre a evolução no ensino-aprendizagem e na possibilidade de utilização futura de uma abordagem de ensino híbrido, ou blended learning, que é uma das tendências da educação do século 21, que segundo Neto (2017) tal abordagem é caracterizada pelo encontro entre ensino presencial, por meio de atividades e resolução de problemas, e estudo online, trazendo uma perspectiva diferente da tradicional onde o professor é o protagonista para um receptor de conhecimento.

No entanto, Castaman e Rodrigues (2020), salientam que a pandemia de certa forma contribuiu para mostrar as dificuldades do ensino no Brasil, principalmente relacionado ao processo de transição do ensino presencial para o remoto. Nem todos os alunos da rede pública de ensino podem ter uma boa conexão com a internet de qualidade para acompanhar as aulas com qualidade, revelando ainda mais as diferenças sociais existentes na sociedade brasileira.

\section{Considerações Finais}

Esse estudo apresenta a experiência vivida no processo de ensino e monitoria durante um evento histórico para o mundo, a pandemia da COVID-19. Apresentou a experiência da inserção e resgate de ferramentas, estratégias e formas de adaptação ao ensino remoto que se impôs devido à necessidade de isolamento social e quarentena. Trouxe reflexão sobre a importância do ensino-aprendizagem e monitoria ladeados aos avanços digitais e das tecnologias de informação e comunicação. Considerou que apesar das angústias e temores, relativos ao ensino remoto e às consequências da pandemia, o processo de ensino utilizando uma abordagem humanística possivelmente contribuiu para a promoção da saúde mental e física. Julgou ser necessário refletir sobre o ensino híbrido.

Portanto, considerou-se o ensino, monitoria e cuidado em tempos da COVID-19 uma experiência única e um importante componente de contribuição para o processo de formação acadêmica. Apesar dos desafios, incertezas, perdas e danos a pandemia não conseguiu parar o ensino. Dessa forma, a experiência vivida com o ensino remoto possibilitou a reflexão sobre os "paradigmas" do presencial e remoto, e sobre a melhor utilização das TICs no cotidiano acadêmico.

Porém, para reflexão mais aprofundada sobre o assunto, seria necessário um estudo com testes estatísticos robustos, delineamento hipotético bem elaborado e amostragem de participantes maior, para verificar a possibilidade de se comparar a eficiência significativa do ensino híbrido comparado ao ensino presencial. Com isso, seria possível indicar se o ensino remoto é tão eficiente quanto o ensino presencial. $O$ desenvolvimento de escalas para mensurar o estresse em estudantes, seria uma forma de avaliar a saúde mental dos discentes pós pandemia, devido ao prolongado tempo de uso das tecnologias e de distanciamento social.

\section{Agradecimentos}

À Universidade Federal da Paraíba, cenário das atividades na elaboração do manuscrito.

\section{Referências}

Andrade, E. G. R., Rodrigues, I. L. A., Nogueira, L. M. V., \& Souza, D. F. de (2018). Contribution of academic tutoring for the teaching-learning process in Nursing undergraduate studies. Revista Brasileira de Enfermagem. 71(4), 1596-603. [Thematic Issue: Education and teaching in Nursing] http://dx.doi.org/10.1590/0034-7167-2017-0736.

Aristovnik, A. Keržǐc c, D., Ravšelj, D., Tomaževi`c, N., \& Umek, L. (2020). Impacts of the COVID-19 Pandemic on Life of Higher Education Students: A Global Perspective. Sustainability, 12(8438), 1-24. 10.20944/preprints202008.0246.v2.

Barreto, A. P. (2008). Terapia Comunitária Integrativa: passo a passo. (3a ed.), Gráfica LCR.

Bessa, B. (2018). Recomece Sextante.

Brasil. Ministério da Saúde (2007). Política Nacional de Humanização da Saúde. Documento Base. Ministério da Saúde. (4a ed.),

Brant, L. (2009). O poder da cultura. Peirópolis. 
Castaman, A. S. \& Rodrigues, R. A. (2020). Educação a Distância na crise COVID - 19: um relato de experiência. Research, Society and Development. 9(6). $10.33448 /$ rsd-v9i6.3699.

Dotta, S (org) (2014). Aulas virtuais síncronas: Condução de webconferência multimodal e multimídia em Educação a Distância. São Paulo: Editora UFABC.

Edital Simplificado no 018 de 11 de agosto de 2020 da Universidade Federal da Paraíba, João Pessoa, 2020 ago. 11. http://www.prg.ufpb.br/prg/codesc/processosseletivos/noticias/edital-simplificado-no-018-2020-cppa-prg-ufpb-monitoria-para-o-ensino-remoto/vf-018-2020-edital-de-monitoria-para-o-ensino-remoto-10de-agosto-de-2020.pdf.

Fawaz, M. \& Samaha, A. (2020). E-learning:Depression,anxiety, and stress symptomatology among Lebanese university students during COVID-19 quarantine. Nursing Forum, 1-6. https://doi.org/10.1111/nuf.12521.

Freire, P. (2020). Pedagogia da autonomia: saberes necessários à prática educativa. (65a ed.), Paz e Terra.

Freire, P. (2020). Educação como prática de liberdade. (47a ed.), Paz e Terra.

Jowsey, T., Fosterb, G. Cooper-Ioeluc, P., \& Jacobs, S. (2020). Blended learning via distance in pre-registration nursing education: A scoping review. Nurse Education in Practice, 44:1-10. 10.1016/j.nepr.2020.102775.

Leigh, J., Vasilica, C., Dron, R., Gawthorpe, D., Burns, E., Kennedy, S. Kennedy, R., Warburton, T., \& Croughan, C. (2020). Redefining undergraduate nurse teaching during the coronavirus pandemic: use of digital technologies. British Journal of Nursing, 29(10), 566-569. https://doi.org/10.12968/bjon.2020.29.10.566.

Lovri'c, R., Farcic, N., Miksic, S., \& Vcecv, A. (2020). Studying During the COVID-19 Pandemic: A Qualitative Inductive Content Analysis of Nursing Students' Perceptions and Experiences. Education. Science. 10(188), 1-18. 10.3390/educsci10070188.

Martini, G. (2017). Dinâmicas de grupos, jogos relacionais: dinâmicas, jogos, brincadeiras terapêuticas testadas em grupos e comunidades. Porto Alegre. Caifcom Editora.

Morcillo, A. J. R., Costa, C. L., Garcia, J. E. M., \& Martínez, M. R. (2020). Experiences of Nursing Students during the Abrupt Change from Face-to-Face to eLearning Education during the First Month of Confinement Due to COVID-19 in Spain. International Journal Environmental Research and Public Health, 17(5519), 1-15. Citado em PubMed. PMID: 32751660.

Murphy, M. P. A. (2020). COVID-19 and emergency eLearning: Consequences of the securitization of higher education for post-pandemic pedagogy. Contemp Secur Policy, 41(3), 492-505. https://doi.org/10.1080/13523260.2020.1761749.

Neto, E. B. (2017). O ensino híbrido: processo de ensino mediado por ferramentas tecnológicas. Ponto e Virgula, (22), 50-72. Disponível em: https://revistas.pucsp.br/index.php/pontoevirgula/article/view/31521/24901.

Othman, N., Ahmad, F., Morr, E. C., \& Ritvo, P (2019). Perceived impact of contextual determinants on depression, anxiety and stress: a survey with university students. International Journal of Mental Health Systems .13(1), 17. https://doi.org/10.1186/s13033-019-0275-x.

Ouzzani, M., Hammady, H., Fedorowicz, Z., \& Elmagarmid, A. (2016). Rayyan — a web and mobile app for systematic reviews. Systematic Reviews, 5:210. 10.1186/s13643-016-0384-4.

Pizzimenti, C. (2017). Cris Pizzimenti. https://www.pensador.com/autor/cris_pizzimenti/.

Prieto, H. \& Saxe, J. G. (2021). A história dos sete homens sábios e o elefante. https://www.esalq.usp.br/visoes-da-ciencia/vc-a-lenda

Resolução No 19 de 06 de agosto de 2020 da Universidade Federal da Paraíba, João Pessoa, 2020 ago. http://www.ccae.ufpb.br/antropologia/contents/do cumentos/resp19-20.pdf.

Resolução No 02 de 22 de fevereiro de 19962020 da Universidade Federal da Paraíba, João Pessoa, 2020 ago. 06. http://www.prg.ufpb.br/antigo/sites/ default/files/Resol u\%C3\%A7\%C3\%A3o\%20N\% C2\%BA\%2002\%20DE\%201996\%20do\%20CONSEPE.PDF.

Stott, A. \& Mozer, M. (2016). Connecting learners online: challenges and issues for nurse education-Is there a way forward? Nurse Educ Today, 39:152-154.

Vianna, R. (2018). EndNote Online - Como Organizar suas Referências. Pontifícia Universidade Católica de São Paulo.

Zhou, P., Yang, X. L., \& Shi, Z. L. (2020). A pneumonia outbreak associated with a new coronavirus of probable bat origin. Nature, 579:270-273. https://doi.org/10.1038/s41586-020-2012-7. 